\title{
Políticas públicas, planejamento e geração do desenvolvimento urbano sustentável: Importância e múltiplas formas de interações
}

\begin{abstract}
A política pública desempenha importante papel enquanto instrumento norteador do planejamento e envolve os mais diversos atores sociais em busca de soluçõe comuns para os problemas urbanos que afetam o interesse coletivo, visto que a exequibilidade do projeto de desenvolvimento urbano sustentável requer esforços igualmente coletivos. Compreender as interações existentes entre a política pública, o planejamento e o desenvolvimento urbano se configuram como elemento facilitador do processo de implementação de tais políticas. Neste sentido, o objetivo do artigo é discutir a importância e múltiplas formas de interações entre as políticas públicas e o planejamento para a geração do desenvolvimento urbano sustentável, estruturando-se como um ensaio teórico, baseado nas inferências de autores como Casula (2017) sobre políticas públicas; Castro et al. (2014) sobre as conexões da política pública e o desenvolvimento; Saravia (2006) e Pereira et al. (1998) sobre gestão pública; Philippi Junior (2012) e Acselrad (1999) sobre desenvolvimento sustentável, dentre outras importantes contribuições que versam sobre estudos urbanos. As informações foram organizadas e fundamentadas em bases teóricas publicizadas a partir da década de 1990, abordando o tema sob a perspectiva metropolitana-urbana. Os resultados obtidos apontam para a necessidade de alinhamento do planejamento urbano com as políticas públicas, envolvendo para tanto a participação efetiva da sociedade nas decisões sobre elas com o objetivo precípuo de alicerçar o desenvolvimento urbano sustentável.
\end{abstract}

\section{Public policies, planning and generation of sustainable urban development: Importance and multiple forms of interactions}

\begin{abstract}
Public policy performs an important role as a guiding tool for planning and involves the most diverse social actors in search of common solutions to urban problems that affect the collective interest, considering the feasibility of the sustainable urban development project requires equally collective efforts. Understand the existing interactions between public policy, planning and urban development as a facilitating element in the process of implementing public such policies. In this sense, the objective of the article is to discuss the importance of multiple forms of interactions between public policies and planning for the generation of sustainable urban development, structuring itself as a theoretical essay, based on the inferences of authors such as Casula (2017) on public policies; Castro et al. (2014) on public policy connections and development; Saravia (2006) and Pereira et al. (1998) on public management; Philippi Junior (2012) and Acselrad (1999) on sustainable development, among other important contributions that deal with urban studies. The information was organized and based on theoretical bases published from the 1990s onwards, addressing the theme from a metropolitan-urban perspective. The results obtained point to the need to align urban planning with public policies, thus involving the effective participation of society in decisions about them, with the primary objective of underpinning sustainable urban development.
\end{abstract}

Keywords: Public Policies; Urban Development; Urban Sustainability.

Topic: Desenvolvimento, Sustentabilidade e Meio Ambiente

Reviewed anonymously in the process of blind peer.
Received: $19 / 03 / 2020$

Approved: 22/04/2020
Márcia Félix da Silva (1D)

Universidade Federal de Campina Grande, Brasil

http://lattes.cnpq.br/2771934125977891

http://orcid.org/0000-0002-4598-5961

mfelixufpb@gmail.com

Gesinaldo Ataíde Cândido (io

Universidade Federal de Campina Grande, Brasil

http://lattes.cnpq.br/2771934125977891

http://orcid.org/0000-0002-3112-0254

gacandido01@gmail.com
Referencing this:

SILVA, M. F.; CÂNDIDO, G. A.. Políticas públicas, planejamento e geração do desenvolvimento urbano sustentável: Importância e múltiplas formas de interações. Revista Ibero Americana de Ciências Ambientais, v.11, n.3, p.332-348, 2020. DOI:

http://doi.org/10.6008/CBPC2179-6858.2020.003.0026 


\section{INTRODUÇÃO}

O desenvolvimento urbano sustentável, tema de constantes debates no meio político, empresarial e acadêmico, requer do poder público um planejamento urbano direcionado à implementação de políticas públicas que impliquem em ações efetivas na melhoria da qualidade de vida da população e, concomitantemente, minimize os impactos da atividade humana sobre o ambiente no intuito de assegurar a sustentabilidade urbana, o que envolve decisões que impactam diretamente sobre o complexo sistema metrópole/cidade.

Buscando responder a esses desafios, novos modelos de gestão têm sido postos pelos gestores públicos, favorecendo a abertura de gestões democráticas que priorizam a participação popular nas decisões sobre investimentos em obras e/ou serviços públicos que beneficiem a coletividade. A adoção desses novos modelos de gestão pública tem trazido como principal consequência a previsão de descentralização do poder e, por conseguinte, o fortalecimento do processo de democratização e de participação popular nas decisões do governo, notadamente no que se refere às políticas públicas de desenvolvimento urbano.

Consideradas celeiros vastos de oportunidades para os mais diversos públicos, "enquanto focos estruturais de 'problemas', as cidades são alvos inevitáveis das ações dos decisores políticos e das políticas públicas" (FERRÃO, 2016). Compreender a dinâmica de funcionamento da cidade para que se possa planejar a infraestrutura de serviços que deverão ser oferecidos para atender à população é, indubitavelmente, de importância crucial.

Destarte, a política pública desempenha importante papel enquanto instrumento norteador do planejamento, sobretudo do planejamento urbano e apesar de não se limitar a uma definição única, destacase a característica de que ela abrange "o conjunto de medidas que um formulador de políticas decide ou não adotar para resolver um problema que se distingue por impactar uma coletividade" (CASULA, 2017), buscando compreender as razões que levam o Estado a agir como age (MARQUES, 2013).

Esse 'conjunto de medidas' que caracteriza a política pública deve ser contemplado pelo planejamento em consonância com as diretrizes da política pública, evidenciando o ciclo interativo e iterativo do processo de política pública e do planejamento, cabendo ao gestor público a escolha de um modelo de governança que priorize a participação dos cidadãos nas decisões sobre políticas públicas que contemple as mais diversas áreas, inclusive com o envolvimento dos setores produtivos, bem como das instituições sem fins lucrativos no projeto de desenvolvimento urbano sustentável.

Castro et al. (2014) reforçam que o processo de desenvolvimento de um país ultrapassa o campo de reflexão da economia, inserindo também elementos relativos à análise das relações sociais, das instituições, e das dinâmicas ambientais e territoriais. Observa-se, assim, a necessidade premente de pactuação sobre os objetivos e metas que orientem a formulação e a implementação de políticas públicas que podem ser reputadas como alicerce do complexo circuito de influências no desenvolvimento. Desse modo, sugerem os autores, as conexões entre as políticas públicas e o desenvolvimento podem ser analisadas se levando em conta cinco grandes dimensões: social, econômica, ambiental, territorial e político-institucional e que serão 
explicitadas no decorrer do texto.

A partir destas considerações iniciais fica evidenciada a necessidade de compreender que o processo de política pública e o planejamento devem estar alinhados e em constante interação para que possam contribuir de forma mais efetiva para o desenvolvimento urbano sustentável. Destarte, o objetivo deste artigo é discutir a importância e múltiplas formas de interações entre as políticas públicas e o planejamento para a geração do desenvolvimento urbano sustentável, configurando-se como elemento facilitador na compreensão do processo de política pública.

\section{METODOLOGIA}

Em termos metodológicos, trata-se de um ensaio teórico, no qual as informações foram organizadas, e fundamentadas em bases teóricas publicizadas a partir da década de 1990, abordando o tema sob a perspectiva metropolitana/urbana, baseado nas inferências de autores como Casula (2017) sobre políticas públicas; Castro et al. (2014) sobre as conexões da política pública e o desenvolvimento; Saravia (2006) e Pereira et al. (1998) sobre gestão pública; Philippi Junior (2012), Acselrad (1999) sobre desenvolvimento sustentável, dentre outras importantes contribuições que versam sobre estudos urbanos.

Além deste conteúdo introdutório, o artigo explora em sua fundamentação teórica os tópicos: políticas públicas e desenvolvimento, fatores de desenvolvimento e desenvolvimento urbano sustentável apresentando suas principias abordagens e relações de complementaridade, seguido das considerações finais ao conteúdo apresentado.

\section{DISCUSSÃO TEÓRICA}

\section{Políticas Públicas e Desenvolvimento}

A participação social nas decisões sobre políticas públicas, a partir da abertura de diálogos entre o poder público e a sociedade, com vistas a encontrar soluções comuns para problemas coletivos, tem propiciado o fortalecimento da democracia participativa, resultando em novas configurações dos modelos de gestão pública.

Os primeiros estudos sobre administração pública foram realizados por Woodrow Wilson, professor de Ciência Política da Universidade de Princeton e que, posteriormente, tornou-se presidente dos Estados Unidos. Sua principal preocupação, nos anos próximos a 1880, era a criação de uma classe administrativa apartidária, selecionada na base do mérito, para, assim, neutralizar o nepotismo e o favoritismo que dominavam a administração pública norte-americana do século XIX (SARAVIA, 2006).

No entanto, a reforma do Estado só se tornou tema central da agenda política mundial a partir da década de 1970, quando o modelo de Estado que vigorava no período pós-guerra nos países desenvolvidos entrou em crise, evidenciando a necessidade de reforma para restabelecer o equilíbrio fiscal e o balanço de pagamento. A proposta inicial para superação da crise foi, simplesmente, a redução do tamanho do Estado e o predomínio total do mercado, ideia que não prosperou devido à constatação de que a solução não estaria 
no desmantelamento do aparelho estatal, mas na reconstrução de um Estado para o século XXI, que pudesse enfrentar os novos desafios da sociedade pós-industrial, garantir o cumprimento dos contratos econômicos, assegurar os direitos sociais e a competitividade de cada país no cenário internacional. Buscava-se, portanto, uma terceira via entre o laissez faire neoliberal e o antigo modelo social-burocrático de intervenção estatal, sobretudo considerando o papel do Estado enquanto instrumento fundamental para o desenvolvimento econômico, político e social de qualquer país (PEREIRA et al., 1998).

$\mathrm{Na}$ América Latina registra-se um número significativo de experiências de ação pública local/territorial voltadas ao desenvolvimento, sendo o caso brasileiro resultante de ações inovadoras, intensificadas a partir da Constituição de 1988 que, com a finalidade de atender às demandas da sociedade por democratização, promoveu maior grau de autonomia para Estados e Municípios (ROVER et al., 2011). Ainda conforme os autores, as décadas de 1980 e de 1990 marcam um período de maior abertura democrática nos municípios brasileiros com o fortalecimento das experiências democráticas construídas com a participação da sociedade civil (demanda organizada, elaboração, planejamento e controle de políticas), o que permitiu o estabelecimento de uma nova relação entre Estado e Sociedade a partir de experiências inovadoras, oportunizando a que novos grupos sociais locais intervenham nas políticas públicas [aspecto positivo], possibilitando, no entanto, a reedição de práticas políticas tradicionais, legitimadas pela 'ilusão de participação' [aspecto negativo].

Salamon (2002) observa que nos últimos cinquenta anos, tanto nos Estados Unidos como em outras partes do mundo, ocorreu uma revolução na tecnologia da ação pública que resultou em uma transformação fundamental não apenas no escopo e escala de ação governamental, como também em suas formas básicas. Corroborando com essa asserção, Saraiva (2006) reforça que nas últimas décadas, a interação entre indivíduos, empresas e outras organizações nacionais e internacionais, bem como entre Estados, tem-se intensificado como consequência do processo de globalização, dos avanços das tecnologias das comunicações e da informática: a telemática (comunicações + informática) fortaleceu a transparência e o consequente controle social das ações do Estado. Ainda conforme o autor, foi a partir do final da Segunda Guerra Mundial que esse processo se tornou mais acelerado, o que exigiu a permanente adaptação das estruturas organizacionais a um contexto com variáveis novas ou modificadas, embora as organizações estatais tenham reagido tardiamente a esse processo, o que resultou na deterioração de sua capacidade de resposta às necessidades e aos anseios da população, afetando a sua credibilidade. Ademais, na esfera pública registrou-se um desejo crescente de participação democrática no processo de tomada de decisões estatais, na sua implementação, no seu controle e nos seus benefícios, que no Brasil se tornou mais evidente a partir da promulgação da Constituição de 1988.

De fato, essas transformações trouxeram como principal consequência a necessidade de redefinição de papeis no âmbito da gestão pública no Brasil que permitiu a abertura de espaços de negociação e de cooperação público-privado que impactaram diretamente nas formas de governo e sobre os instrumentos de participação democrática, sendo as políticas públicas a principal representação do ressignificado do papel do Estado no que se refere às políticas de desenvolvimento. 
Sob essa perspectiva, Colebatch et al. (2010) observam que quando se fala em governo o termo 'política' é utilizado para apresentar o processo de governo como um padrão de ação sistemática orientada para interesses coletivos específicos. Trata-se de um conceito central para descrever o governo em termos autoritários e instrumentais: os governos reconhecem problemas e tomam decisões concernentes à autoridade pública sobre os recursos para lidar com esses problemas. A 'política' expressa, então, essas decisões. Em certa medida, a perspectiva política é vista como alternativa à perspectiva mais tradicional de 'política' sobre o governo que a vê como uma luta competitiva pelo poder e pela capacidade de alocação de recursos públicos que o acompanha. Ainda conforme os autores, enquanto conceito, a política deveria ser considerada o que Lévi-Strauss denominou 'um significante flutuante', ou seja, o contexto e as pessoas envolvidas determinam o seu significado, fazendo-se necesssário compreender o contexto específico para entender como o trabalho da política é realizado.

Parada (2006) dilucida que, na prática, tanto a política quanto as políticas públicas estão diretamente relacionadas ao poder social. No entanto, enquanto a política alcança maior abrangência em relação ao poder geral, as políticas públicas são bem mais pontuais na busca de soluções específicas para questões de natureza pública, embora quando a política [enquanto sistema] é mais demagógica e menos moderna, as políticas públicas não são incluídas nas ações de governo. Ainda conforme o autor, "a política pode ser analisada como a busca de estabelecer políticas públicas sobre determinadas questões, ou influenciá-las. Ao mesmo tempo, uma parte fundamental do trabalho do governo refere-se à concepção, gestão e avaliação de políticas públicas" (PARADA, 2006).

Cochran et al. (2014) esclarecem que a política pública pode ser descrita como a estrutura geral dentro da qual as ações do governo são realizadas para alcançar objetivos públicos. Em outras palavras, as políticas são cursos de ação intencionais concebidos em resposta a um problema percebido, sendo as políticas públicas filtradas por meio de um processo político específico, posto em prática através de leis, medidas regulatórias, cursos de ação governamental e prioridades de financiamento e que podem ser tipificadas, conforme Lowi (1972), como distributiva, reguladora, redistributiva e construtiva.

Souza (2007) explica que as políticas distributivas se referem às decisões tomadas pelo governo que geram impactos mais individuais do que universais, privilegiando determinados grupos sociais ou regiões. Já as políticas regulatórias envolvem [como o próprio nome sugere] os mecanismos de regulação como a burocracia, políticos e grupos de interesse. 0 terceiro tipo de política, a redistributiva, refere-se às políticas sociais universais, o sistema tributário, o sistema previdenciário, sendo de mais difícil encaminhamento. 0 quarto tipo se refere às políticas constitutivas e, nesse caso, estão relacionadas aos procedimentos. Cada política pública gera pontos ou grupos de vetos e de apoios diferentes e se processa dentro do sistema político de forma também diferente [impactando sobre o modelo de governança instituído pelo gestor].

Foi ao longo dos anos de 1980 que se registrou o fortalecimento progressivo da concepção da atividade governamental mais eficiente, sendo a ação baseada no planejamento substituída pela ideia de política pública e, nesse sentido, sem descartar os aspectos positivos do planejamento, a dinâmica estatal se desenvolveu a partir da adoção de alguns conceitos derivados das transformações operadas no campo da 
tecnologia, da economia e da administração, permitindo que a democratização do sistema político fosse facilitada pelo uso da tecnologia: os processos de descentralização e de participação foram simplificados do ponto de vista operacional, tornando as mudanças sociais possíveis e desejáveis (SARAVIA, 2006).

Para Buarque (2002), a descentralização expressa uma transformação profunda na estrutura de poder e é bem mais ampla do que a desconcentração - embora se observe que os dois modelos sejam utilizados pelas instituições no Brasil - posto que a desconcentração apenas distribui a responsabilidade executiva de atividades, programas e projetos sem transferir a autoridade e a autonomia decisória, ou seja, na descentralização ocorrem mudanças na escala de poder para unidades menores, inclusive com repasse de autonomia e de poder decisório entre instâncias públicas e, da mesma forma, para instituições privadas. Já na desconcentração ocorre a transferência da responsabilidade executiva para unidades menores, sem, no entanto, haver repasse do poder decisório e da autonomia de escolha.

A ineficácia da descentralização pode ser percebida quando apresenta um enquadramento legal fraco, ausência de vontade política, capacidade de implementação inconsistente, autoridades locais com poucos recursos, pessoal malformado, representação política inadequada (UN-HABITAT, 2016).

Sob essa perspectiva, a política pública também pode ser definida como um sistema de decisões públicas, cujo propósito principal é o de estabelecer ações ou omissões, preventivas ou corretivas, visando a manter ou modificar a realidade de um ou mais setores da sociedade, a partir do estabelecimento de objetivos e estratégias de atuação e da alocação dos recursos necessários para que esses objetivos possam ser alcançados, com a finalidade precípua de consolidar a democracia, a justiça social, a manutenção do poder e a felicidade das pessoas, sendo estes os elementos que orientam as inúmeras ações que compõem determinada política, o que alguns autores denominam de metapolítica (SARAVIA, 2006).

Na prática, o trabalho de política consiste não apenas na busca pela solução de problemas, mas trata também da identificação de áreas de preocupação e da aplicação de técnicas conhecidas de governança (COLEBATCH et al., 2010). Nesse sentido, o estudo de uma única política pública exige pelo menos um duplo canal de análise: o objetivo do formulador da política quando toma a decisão de empreender um ciclo de ação específico (natureza da política pública) e as características dos atores envolvidos no processo (CASULA, 2017).

Saravia (2006) afirma que apesar de o formato concreto de uma política pública depender de cada sociedade específica, é possível identificar componentes comuns, quais sejam: a) componente institucional: quem elabora ou toma decisões sobre uma política pública é sempre uma autoridade formal, legalmente constituída no âmbito da sua competência, sendo ela coletivamente vinculante; b) componente decisório: a política é um conjunto-sequência de decisões, relacionadas à escolha de fins e/ou meios, de longo ou curto alcance, em uma situação específica e como resposta a problemas e necessidades da sociedade; c) componente comportamental: refere-se à ação ou inação, à decisão de fazer ou não fazer nada; embora uma política seja acima de tudo, um curso de ação e não apenas uma decisão singular; d) componente causal: refere-se aos resultados de ações que têm efeitos no sistema político e social.

De modo geral, as diretrizes para diversas políticas, em especial as sociais têm apontado para a 
instituição de um Estado de bem-estar, cujo principal objetivo seria o de prover a universalização dos direitos sociais (MORONI, 2009). Assim, no âmbito social, as mudanças devem estar centradas no fortalecimento do papel do Estado como formulador e financiador das políticas públicas, com destaque para o desenvolvimento da capacidade catalisadora dos governos em atrair a comunidade, as empresas e as organizações não governamentais para compartilharem a responsabilidade pela execução dos serviços públicos, sobretudo nas áreas de saúde e educação (PEREIRA et al., 1998).

Uma das implicações desta política tem sido a abertura de espaços para práticas participativas, sobretudo nas áreas de políticas públicas de saúde, assistência social, urbanas e de meio ambiente, sendo os Conselhos de política (instituições híbridas compostas por atores do poder Executivo e membros da sociedade civil) e os orçamentos participativos os que mais influenciaram as políticas públicas no Brasil (AVRITZER, 2009).

De fato, "a legitimidade da democracia participativa se fundamenta no reconhecimento do direito à participação, da diversidade dos sujeitos políticos coletivos e da importância da construção do espaço público de conflito/negociação" (MORONI, 2009). Ainda conforme o autor, o sistema descentralizado e participativo se configura como espaço essencialmente político de representações governamentais e não governamentais, incumbidas de elaborar, deliberar e fiscalizar a implementação de políticas públicas nas esferas nacional, estadual e municipal.

Castro et al. (2014) dilucidam que embora o período de 1930 a 1980 seja considerado importante no desenvolvimento do Brasil, foi só a partir do início do Século XXI que o país passou a experimentar a formulação e a implementação de políticas públicas voltadas à promoção do desenvolvimento em um sentido socialmente mais inclusivo do que o praticado anteriormente, ou seja, conceitualmente, a política pública deve reconhecer que há uma área ou domínio da vida que não é privada ou somente individual e, portanto, as demandas de interesse público devem ser preponderantes na formulação da política pública, em oposição àquelas de interesses privados.

Avritzer (2009) observa três grandes tendências que regem a relação entre sociedade civil e políticas participativas no Brasil: 1) gestões participativas exitosas contribuem para a continuidade administrativa dos que as implantaram, contribuindo inclusive para a reeleição do candidato do partido; 2) as experiências participativas ainda se restringem a limites políticos regionais, com destaque para os Estados do Rio Grande do Sul, São Paulo e Minas Gerais, sendo ainda incipientes as experiências registradas na região Nordeste; 3 ) as políticas participativas não se restringem aos conselhos e aos orçamentos participativos, mas a uma pluralização de formatos participativos, a exemplo da diversidade de audiências públicas em âmbito estadual e federal.

Nesse sentido, "o estudo das políticas públicas e sua compreensão não deve limitar-se à mera reconstrução do ciclo de vida de uma política pública. Pelo contrário, deve ajudar a compreender a estruturação mais geral do sistema político e a atual forma de governo" (CASULA, 2017). Quando consideradas sob os aspectos analíticos, as políticas públicas envolvem, ainda que implicitamente, dois tipos de causalidade, sendo a primeira referente às causas do problema objeto da política e a segunda se refere 
ao efeito que se pretende alcançar com a implementação da política para a solução do problema (MARQUES, 2013).

Lima et al. (2014) sugerem que na análise das políticas públicas pode ser também utilizada a abordagem sequencial ou ciclo de políticas públicas. Trata-se de uma ferramenta analítica na qual a política pública é apresentada em três etapas: 1) Formulação: definição e escolha dos problemas que merecem a intervenção estatal, com possíveis soluções ou alternativas para a tomada de decisão; 2) Implementação e avaliação: refere-se à execução das decisões adotadas na etapa de formulação; 3) Avaliação: interrogação sobre o impacto da política [feedback dos resultados alcançados].

Na prática, para compreender os problemas inerentes às políticas públicas, dois aspectos devem ser considerados: a ação intencional dos atores envolvidos na busca pela realização de objetivos e o imperativo de justificação/legitimação, visto que a observância dessas características corrobora para a eficácia - objeto e desafio para os debates coletivos (GODARD, 1997).

A adoção da gestão participativa na esfera pública, sobretudo na gestão municipal, é, indubitavelmente, ponto de interseção das concepções dos autores que embasaram este estudo, visto que a necessidade de atendimento às demandas da sociedade por democratização busca promover a abertura de espaços de diálogos e de negociação com o poder público, sobretudo no que se refere às políticas públicas, resultando em planejamentos de ações mais efetivas para a solução de problemas que afetam a coletividade. De fato, observa-se, que a interação entre governantes e governados promovida pela gestão participativa poderá resultar em importantes parcerias público-privadas para atender a demandas por serviços de infraestrutura urbana, que contribuam para o bem-estar social da população, e-cooperando de forma positiva para o desenvolvimento urbano sustentável.

\section{Fatores de Desenvolvimento}

As decisões sobre políticas públicas de desenvolvimento para atender às demandas da sociedade por serviços e infraestrutura urbana, requer dos gestores públicos o planejamento das ações que serão implementadas. Para tanto, faz-se necessária a interação entre governo e sociedade visando o estabelecimento de parcerias para o alcance dos objetivos e metas que orientem a formulação e a implementação de políticas públicas.

Castro et al. (2014) sugerem que na análise do desenvolvimento devem ser consideradas cinco grandes dimensões: social, econômica, ambiental, territorial e político-institucional e que estão em constante interação quais sejam: 1) A dimensão social contempla as políticas sociais voltadas aos programas e ações do Estado que se materializam na garantia da oferta de bens e serviços, nas transferências de renda e na regulação de elementos do mercado, buscando-se a justiça social mediante a proteção social (seguridade social) e a promoção social (igualdade de oportunidades); 2) A dimensão econômica envolve as políticas macroeconômicas e de financiamento que buscam garantir os objetivos de estabilidade macroeconômica e de crescimento, podendo ainda dar curso e velocidade aos investimentos em produção e consumo de massa e investimentos em infraestrutura econômica e social e de potencialização do processo 
de inovação e fortalecimento dos encadeamentos produtivos; 3) A dimensão ambiental, por sua vez, enfatiza a sustentabilidade, associando o desenvolvimento produtivo a um meio ambiente equilibrado e saudável pelo uso adequado dos recursos naturais, sendo as políticas públicas direcionadas a programas que busquem a recuperação e preservação do meio ambiente, visto que, na ocorrência de problemas ambientais, as populações mais pobres são as mais atingidas, evidenciando a necessidade de aperfeiçoamento das políticas públicas; 4) A dimensão territorial abrange as políticas públicas que buscam, essencialmente, distribuir pelo território nacional condições mais adequadas de acesso a bens e serviços e a redistribuição de oportunidades e renda, contribuindo para o fortalecimento das potencialidades de cada território; 5) A dimensão políticoinstitucional está relacionada à promoção da inserção internacional soberana e o contínuo fortalecimento do Estado e das instituições em um regime democrático que estimule a participação e a inclusão social.

Ressaltam os autores (CASTRO et al., 2014) que os resultados esperados do processo de desenvolvimento - compreendido como a capacidade de uma sociedade específica de superar os entraves à realização de suas potencialidades - quando consideradas essas cinco dimensões, dependerão das combinações de políticas públicas conduzidas pelo diversos Estados nacionais. Nesse caso, as conexões entre as variáveis estão diretamente relacionadas ao tamanho e à qualidade das políticas públicas envolvidas, visto que dependendo do alcance de sua cobertura, da qualidade dos bens e serviços ofertados à população, e da abrangência do investimento público conduzido pelo Estado, a política pública se torna elemento importante a ser considerado para o ritmo de expansão da atividade (crescimento econômico) e também para a qualidade dessa expansão (aumento da produtividade).

De fato, a análise das políticas públicas a partir de cinco dimensões - social, econômica, ambiental, territorial e político-institucional -, conforme sugerido por Castro et al. (2014), revela-se como instrumento facilitador para a compreensão entre as conexões da política pública e o desenvolvimento.

Quando considerada a gestão de políticas públicas na esfera municipal, quer seja centralizada nos administradores políticos municipais ou através de mecanismos de participação e representação da sociedade na governança local, tornam-se evidentes as potencialidades da gestão municipal para a promoção do desenvolvimento, bem como as limitações relativas à produção de melhores resultados na escala territorial quando comparados àqueles alcançados em escalas superiores à municipal. Assim sendo, novos espaços institucionais têm sido instituídos para a promoção da gestão do desenvolvimento local (ROVER et al., 2011).

Observa-se, por conseguinte, que a instituição de políticas públicas que tenham por objetivo a implementação de cidades sustentáveis requer conhecer o governo municipal e seus processos de formulação, implantação e avaliação de políticas (JORGE et al., 2014).

Além disso, compete ao Estado a promoção de ações que corroborem para que os novos ciclos de desenvolvimento e o aumento da produtividade sejam virtuosos, sobretudo em relação ao uso dos recursos naturais, ao incremento da base tecnológica e à distribuição de renda, cabendo-lhe, portanto, propiciar as condições para o desenvolvimento econômico sustentado e garantir os recursos financeiros e administrativos necessários para reduzir a pobreza e as graves desigualdades sociais, o que poderá viabilizar 
o encerramento do círculo vicioso do 'crescimento empobrecedor' que caracterizou a América Latina no passado (PEREIRA et al., 1998).

Para Miranda (2009), ao instituir mecanismos legais para a construção de uma nova Política de Desenvolvimento Urbano, o Governo Federal expôs a necessidade de tornar evidente a diversidade das relações existentes entre cidades e territórios, visando a propiciar a articulação de políticas de desenvolvimento urbano e regional, embora, na concretização dessas políticas, observe-se a ausência das interações necessárias à promoção de um desenvolvimento mais equilibrado e socialmente justo em todo o território nacional. Além disso, as especificidades regionais no desenho da política nacional são incipientes, o que dificulta a implementação de políticas e instrumentos urbanísticos regulamentados a partir do Estatuto da Cidade.

Nesse sentido, Acselrad (1999) enfatiza que o crescimento urbano sem investimentos em infraestrutura afeta negativamente a oferta de serviços à população, por não acompanhar o crescimento da demanda. Por conseguinte, a falta de investimentos na manutenção dos equipamentos urbanos resultará na acentuação do déficit de serviços, gerando como consequência a segmentação socioterritorial entre populações atendidas e não atendidas por tais serviços.

Compreender a importância das políticas públicas para o desenvolvimento urbano requer a adoção de uma nova postura dos atores sociais que são impactados pelas decisões sobre investimentos em obras e serviços de infraestrutura e em programas sociais instituídos pelo gestor público municipal, visto que a participação da sociedade e da iniciativa privada no processo de decisões que impactam sobre a coletividade requer um sistema de governo baseado na cooperação e na responsabilidade compartilhada entre o Estado, o mercado e a sociedade civil organizada, cabendo, portanto, ao gestor público determinar os limites em que essa participação contribuirá efetivamente para a governabilidade que resulte no desenvolvimento urbano.

Destarte, a análise do desenvolvimento a partir das dimensões social, econômica, ambiental e territorial sugerida por Castro et al. (2014), possibilita a obtenção de uma visão panorâmica dos problemas que afetam a coletividade, permitindo a construção de cenários que retratem mais fidedignamente a realidade dos problemas prioritários que precisam de soluções imediatas e que, portanto, devem ser contemplados no planejamento das ações da política pública que efetivamente atendam às demandas da sociedade, contribuindo de forma preponderante para o desenvolvimento urbano sustentável.

\section{Desenvolvimento Urbano Sustentável}

As discussões relativas ao desenvolvimento urbano têm chamado à atenção de estudiosos de diversas áreas, na tentativa de oferecer alternativas que possam conciliar o desenvolvimento das cidades e a promoção da qualidade de vida do cidadão sem, no entanto, comprometer a sustentabilidade dos recursos naturais disponíveis.

De fato, o conceito de desenvolvimento sustentável vem sendo utilizado de modo indiscriminado e aparentemente aceito por todos os setores sociais - de ecologistas a empresários - consequência da formação de um consenso dissimulado, desvinculando-o das condições sócio históricas que o originaram. 
Além disso, os conflitos entre os valores políticos e éticos nos diferentes significados desse conceito vêm sendo dissolvidos pela generalização e esvaziamento do termo (CARVALHO, 2010).

Em face dessas constatações, é necessário encarar os problemas ambientais como parte de um cenário maior: a sustentabilidade. No entanto, quando o conceito de desenvolvimento sustentável é aplicado no contexto das cidades, observa-se que os principais impactos ambientais negativos são gerados nesses espaços, consequência da concentração das ações humanas, evidenciando a necessidade de se promover ações que possibilitem a mitigação desses impactos a partir da compactação das cidades, o que permitiria o controle da atuação de grupos de população sobre os recursos naturais não renováveis, dos desperdícios e poluições, sem dispensar a cooperação da comunidade na busca pelo equilíbrio, pela maior sustentabilidade no desenvolvimento urbano e na melhoria da qualidade de vida (JORGE et al., 2014).

Assim, vê-se reforçada a necessidade de promoção de políticas públicas que propiciem a interação entre o Estado, a sociedade civil e a iniciativa privada no processo de decisão sobre alternativas para o desenvolvimento urbano, sem dispensar atenção aos princípios de sustentabilidade.

De fato, embora os argumentos habituais sobre o futuro do mundo seja a 'mudança social para a sustentabilidade', mudar o mundo é uma aspiração, sustentar o mundo é uma necessidade. No entanto, sem especificar o que é bom, o que deve ser mudado e o que deve ser mantido, tornam contraditórias as duas aspirações: a sustentabilidade significa condições de continuidade duradoura, enquanto a mudança social gera descontinuidades (JAMES, 2015).

Bossel (1999) afirma que a única alternativa à sustentabilidade é a insustentabilidade. É urgente que o objetivo do desenvolvimento global concentre de forma explícita a atenção na sustentabilidade. Para tanto, o conceito tem que ser traduzido nas dimensões práticas do mundo real para torná-lo operacional. É preciso reconhecer a presença ou ausência de sustentabilidade, ou de ameaças à sustentabilidade dos sistemas e utilizar indicadores adequados para fornecer essa informação e um panorama de onde estamos [e onde pretendemos chegar] em relação ao objetivo da sustentabilidade.

Na prática, o que se observa em relação ao discurso da sustentabilidade é que ele não será socialmente aceitável ou socialmente viável se for sobre menos consumo, redução da economia e dos lucros e/ou desaceleração econômica. A narrativa da sustentabilidade com ênfase na qualidade ambiental inalterada ao longo do tempo, sem perda de bem-estar material e ainda exibindo algum ganho social, torna o conceito impraticável (RIDELL, 2004), sobretudo quando consideradas as peculiaridades do espaço urbano.

Nesse sentido, alcançar prosperidade econômica e ao mesmo tempo preservar os recursos naturais e o meio ambiente, configura-se como outro grande desafio, visto que a efetivação de mudanças dessa magnitude requer a aplicação de um conceito de política que vá além da imposição de regras e limites e que não seja apenas punitiva (THOMAS, 2014). Assim, a consciência dos limites da natureza e da sua amplitude planetária requer novas políticas e posturas que impactem sobre o modelo de desenvolvimento que contemple a continuidade do funcionamento da economia em médios e longos prazos (BUARQUE, 2002).

Sachs (1995) observa que "enquanto persistirem enormes disparidades sociais, o crescimento permanecerá, com certeza, uma condição necessária, embora de modo algum suficiente, do 
desenvolvimento, cujos aspectos distributivos e qualitativos não podem ser negligenciados". Nesse cenário, os limites ecológicos devem ser reconhecidos em termos de produção e consumo economicamente sustentáveis: 'mais output' não significa necessariamente 'bom output'. Desse modo, as inovações tecnológicas com vistas ao desenvolvimento sustentável devem ter como base o respeito aos valores fundamentais de sustentabilidade - resistência dos ecossistemas locais, mitigação de impactos causados por mudanças climáticas, eficiência energética e segurança alimentar, além da capacidade da população local de influir na resolução de problemas (FUNTOWICZ et al., 2010), através de um processo de corresponsabilização, coparticipação e codecisão sobre políticas públicas que atendam aos interesses coletivos sem prejuízos ao meio ambiente.

Assim, a solução da crise ambiental atual requer um novo estilo de desenvolvimento sustentável, alicerçado em "uma nova cosmovisão sócio histórica, biocêntrica, solidária, crítica; uma nova racionalidade que demanda uma nova revolução do pensamento, das formas valorativas e éticas associadas e das formas de organização social" (LUZZI, 2010). Nesse contexto, a ação humana ecologicamente sustentável estaria consubstanciada em valores que contemplem o respeito à natureza através da redução dos impactos prejudiciais às condições naturais essenciais à vida, devendo, portanto, reputar os princípios de solidariedade e de responsabilidade como qualidades das suas intervenções e ações (ROSA, 2009).

Nesse sentido, Malheiros et al. (2012) reconhecem que, na prática, o paradigma do desenvolvimento sustentável implica na necessidade de atuação em ambientes de relações complexas: governo-sociedade, sociedade-sociedade, sociedade-indivíduo, sociedade-natureza e natureza-natureza; na esfera local; com foco na integração dos componentes do desenvolvimento sustentável e levando-se em conta o componente temporal nas decisões (crescimento das taxas de poluição, capacidade de resiliência dos ecossistemas reduzida).

Acselrad (1999) recorda que os debates sobre desenvolvimento sustentável das cidades surgiu a partir de rearticulações políticas em que alguns atores envolvidos na produção do espaço urbano buscaram dar legitimidade a suas perspectivas, tornando evidente a compatibilidade das discussões com os propósitos de promover durabilidade ao desenvolvimento, em conformidade com os princípios estabelecidos pela Agenda 21, instituída na Conferência da Organização das Nações Unidas sobre Desenvolvimento e Meio Ambiente. Nessa perspectiva, registrou-se concomitantemente uma 'ambientalização' do debate sobre políticas urbanas e um movimento em sentido oposto, com a entrada crescente do discurso ambiental nas questões urbanas.

De fato, observa-se que as áreas urbanas estão surgindo com bases privilegiadas para uma ação ambiental efetiva. Algumas cidades já sinalizam a adoção de medidas contra as mudanças climáticas, influenciando políticas e práticas para redução das emissões de gases de efeito estufa na esfera global. Também se vem registrando a participação efetiva de universidades, empresas privadas, fundações de pesquisa, organizações filantrópicas, organizações comunitárias e grupos de cidadãos engajados em ações que visem à sustentabilidade urbana. Assim, uma nova agenda urbana com conjuntos bem combinados de princípios e recomendações pode exercer um papel catalisador mais forte para novas parcerias e uma 
transição bem gerenciada para o desenvolvimento urbano sustentável, consequência da percepção de que a urbanização não é uma ameaça ou um processo a ser reduzido: quando bem administrada, a urbanização pode atuar como uma força transformadora em direção a sociedades mais sustentáveis (UN-HABITAT, 2016).

Embora se reconheça a importância das cidades na história da humanidade e no desenvolvimento contemporâneo, o grande desafio é identificar soluções sistemáticas para questões de governança urbana, considerando a complexidade dos problemas que as cidades, as sociedades civis, os agentes econômicos e as organizações políticas precisam enfrentar e que exigem um conjunto de abordagens diferentes, baseadas no reconhecimento do caráter massivamente interconectado das redes sociais urbanas, das redes de infraestrutura e suas dinâmicas no tempo, visto que a complexidade dos problemas urbanos requer ênfase na dinâmica social e econômica da auto-organização, do livre mercado e a vida cívica, sem hierarquia topdown (BETTENCOURT, 2015), sobretudo se for levado em conta que "todos os assentamentos urbanos enfrentam uma crise prática de sustentabilidade, assim como os seres humanos enfrentam uma crise abrangente da vida social neste planeta" (JAMES, 2015).

Clementino (2016) explica que, nos últimos 20 anos, mudanças significativas nos processos de gestão urbana vêm sendo registradas, tais como (1) a ampliação do papel dos municípios no planejamento e na gestão urbana; (2) iniciativas para a implantação de mecanismos para permitir o avanço dos processos de descentralização das políticas públicas e de participação social no planejamento urbano do município; e (3) crescimento das preocupações com as questões ambientais. No entanto, não têm sido apresentadas soluções efetivas para os problemas estruturais peculiares às áreas urbanas (seletividade do acesso ao solo, crescente irregularidade fundiária, visão fragmentada do território, valorização desigual do solo em consequência de práticas especulativas abusivas, apropriação privada de investimentos públicos; expansão urbana desordenada e periférica), o que tem resultado no comprometimento dos recursos naturais. Na prática, as experiências mais recentes não têm apontado para diretrizes que visem a integrar o desenvolvimento regional e urbano.

Nesse contexto, a Organização das Naçoes Unidas (UN-HABITAT, 2016) aponta que as áreas urbanas enfrentam quatro grandes desafios ambientais: 1 ) prover equitativamente a oferta de serviços públicos; 2 ) abordar os riscos ambientais, da poluição à mudança climática; 3) reduzir os efeitos adversos das transformações da terra no uso de recursos, biodiversidade e ecossistemas; e 4) responder ao chamado global de descarbonização e uso mais racional dos recursos. Sob essa perspectiva, observa-se que a governança urbana proporciona um desenvolvimento sustentável quando prioriza o meio ambiente, além de ser participativa, responsável, transparente, eficaz e eficiente, equitativa e inclusiva, respeitando o estado de direito, o que evidencia que o modelo atual de urbanização é, de fato, insustentável.

Ainda de acordo com o relatório da Organização das Naçoes Unidas, em 1990, 43\% da população mundial habitava em áreas urbanas, percentrual elevado para 54\%, em 2015, sendo o processo de urbanização acompanhado por avanços socioeconômicos. No entanto, as grandes e megacidades não são as que mais crescem, nem são anfitriãs da maioria da população urbana mundial, sendo as médias e pequenas cidades, com menos de um milhão de habitantes, as que mais registram crescimento, representando $59 \%$ da 
população urbana mundial (UN-HABITAT, 2016). Na América Latina, o Brasil é o país mais urbanizado: $86,53 \%$ de sua população vivem nas áreas urbanas, consequência do processo de estruturação das cidades iniciado na década de 1950.

Cabe ressaltar que embora as áreas urbanas ocupem apenas 3\% a 4\% da superfície da terra, elas são centros de inovação que geram mais de $80 \%$ do Produto Interno Bruto (PIB) mundial e abrigarão quase $66 \%$ da população mundial até o ano de 2050, provocando impactos no bem-estar humano e ambiental da escala local à global em níveis sem precedentes. De fato, a alta concentração de atividades humanas em áreas urbanas traz como consequências grandes fluxos transfronteiriços de pessoas, utilização mais intensa de recursos naturais, elevação da produção de bens e serviços (incluindo múltiplas infraestruturas essenciais e fornecimento de alimentos), dentre outros fatores, cujos impactos ultrapassam as fronteiras administrativas urbanas (ADVISORY, 2018).

Salat (2017) alerta que o processo de urbanização rápida está em confronto com um triplo desafio: velocidade, escala e escassez de recursos. Isso significa que nos próximos 20 anos, um milhão de pessoas, por semana, serão urbanizados, sendo adicionado a esse cenário as ameaças da mudança climática e a exaustão de recursos.

Nessa perspectiva, o desenvolvimento urbano sustentável requer o equilíbrio entre o crescimento populacional e o meio ambiente, o que perpassa pela solução de problemas decorrentes da falta de investimentos em infraestrutura e saneamento. É necessário desenvolver a cidade em favor da população mais pobre, por conseguinte, mais carente da assistência do Estado.

Destarte, Wilheim (2008) afirma que "a contiguidade entre riqueza e pobreza é extremamente óbvia nas cidades, dramaticamente desnudando a injustiça de modelos econômicos e diminuindo o entusiasmo por sucesso econômico da sociedade como um todo".

Acselrad (1999) ao se manifestar sobre o debate contemporâneo acerca do desenvolvimento urbano sustentável identificou diversas articulações lógicas entre a reprodução das estruturas urbanas e sua base especificamente material, tendo sido encontradas especificamente três representações distintas da cidade, que correspondem a diferentes sentidos do que se pretende legitimamente capaz de dar durabilidade à integridade do urbano: 1. A representação tecno-material das cidades: no processo de transição a sustentabilidade urbana está associada à reprodução adaptativa das estruturas urbanas, com foco no ajustamento das bases técnicas das cidades e em modelos de 'racionalidade ecoenergética' ou de 'metabolismo urbano'; 2. A representação como espaço da 'qualidade de vida': os aspectos de qualidade de vida estão relacionados a componentes não mercantis, com destaque aos que se referem às implicações sanitárias das práticas urbanas; 3 . A representação como espaço de legitimação das políticas urbanas: a ideia de sustentabilidade está associada às condições de reprodução da legitimidade das políticas urbanas.

Nesse cenário, as novas configurações das cidades se caracterizam pela hierarquização territorial, partindo do local para o global, destacando-se a importância do local no desenvolvimento dos processos de inovação no mundo contemporâneo, sendo a lógica do desenvolvimento baseada no acesso à informação. Assim sendo, a cidade sustentável deve priorizar o atendimento aos objetivos sociais ambientais, políticos, 
culturais, econômicos e físicos dos seus cidadãos: uma cidade sustentável não se resume a um conglomerado de construções sustentáveis, mas à incorporação de parâmetros de sustentabilidade que resulte de parcerias público-privada, visto que a sustentabilidade urbana requer a implementação de políticas públicas que promovam o equilíbrio entre os extratos populacionais, minimizando os impactos das desigualdades sociais. O grande desafio dos governos e que também deve ser pauta de toda sociedade é, de fato, a construção de cidades mais justas e inclusivas (LEITE, 2012).

De fato, a complexidade do 'sistema cidade' requer estudos mais bem acurados, que levem em conta as interferências dos indivíduos sobre a dinâmica desse sistema, visto que são os habitantes das cidades que estabelecem as relações sociais que justificam a atratividade do espaço urbano. A discussão acerca das interações entre o planejamento e a política pública a partir das concepções utilizadas nesse estudo evidencia a importância de se debater as cidades como um complexo objeto de estudo para gestores públicos, planejadores, urbanistas, dentre tantos outros segmentos da sociedade corresponsáveis pela implementação de ações que visem ao desenvolvimento urbano sustentável.

\section{CONCLUSÕES}

A ocupação desordenada do espaço urbano traz como principal consequência a escassez de determinados recursos naturais. Encontrar soluções exequíveis que propiciem qualidade de vida à população residente em áreas urbanas, minimizem os impactos da atividade humana sobre o ambiente e propiciem o desenvolvimento urbano sustentável, ainda se configuram como desafios que requerem maior atenção dos formuladores de políticas públicas e dos gestores públicos.

As questões postas nesse estudo sobre a interação necessária entre o planejamento e as políticas públicas evidenciaram a importância de debater a gestão pública sob uma nova perspectiva que priorize a participação social nos processos de negociação que envolva decisões sobre políticas públicas de bem-estar social e das demais áreas que devem ser atendidas pelo poder público, sem prejuízos ao desenvolvimento urbano sustentável.

Muito além da análise do papel do Estado nas decisões sobre planejamento e políticas públicas estão as relações sociais de coparticipação, cooperação e corresponsabilidade estabelecidas, ainda que tacitamente, entre o poder público e a sociedade nas decisões sobre políticas públicas, tão necessárias ao se debater questões relativas ao atendimento das demandas da sociedade e, concomitantemente, do desenvolvimento urbano sustentável.

Indubitavelmente, a condução do processo de negociação e a abertura de diálogos entre o poder público e a sociedade visam, sobretudo, o fortalecimento do processo democrático e a consolidação de um modelo de gestão participativa que evidencie o protagonismo da população na solução de problemas que afetam o interesse coletivo.

Ações planejadas a partir de cenários desenhados com base nas demandas sociais por serviços e infraestrutura urbana que repercutam a participação da sociedade na identificação de problemas e em projetos para a melhoria da qualidade de vida tornam o planejamento das ações de política pública mais 
eficiente. Desse modo, o alinhamento de objetivos e metas do planejamento com as ações de políticas deve ser perseguido pelos gestores públicos, sobretudo quando as decisões são tomadas com respaldo da sociedade a partir de uma gestão democrática e participativa que permita dar voz à população nas decisões governamentais.

\section{REFERÊNCIAS}

ACSELRAD, H.. Discurso da Sustentabilidade Urbana. Revista Brasileira de Estudos Urbanos e Regionais, Recife, n.1, p.79, 1999. DOI: https://doi.org/10.22296/2317-1529.1999n1p79

ADVISORY. Committee for Environmental Research \& Education. Sustainable urban systems: articulating a longterm convergence research agenda. Washington: Sustainable urban systems subcommittee, 2018.

AVRITZER, L.. Sociedade civil e participação no Brasil democrático. In: AVRITZER, L.. Experiências nacionais de participação social. São Paulo: Cortez, 2009.

BETTENCOURT, L. M. A.. Cidades como sistemas complexos. In: FURTADO, B. A.; PATRÍCIA A. M.; SAKOWSKI, M. H. T.. Modelagem de sistemas complexos para políticas públicas. Brasília: IPEA, 2015.

BOSSEL, H.. Indictors for sustainable development: theory, method, applications. Ottawa: International Institute for Sustainable Development, 1999.

BUARQUE, S. C.. Construindo o desenvolvimento local sustentável. Rio de Janeiro: Garamond, 2002.

CARVALHO, I. C. M.. Os sentidos de 'ambiental': a contribuição da hermenêutica à pedagogia da complexidade. In: LEFF, E.. A complexidade ambiental. 2 ed. São Paulo: Cortez, 2010.

CASTRO, J. A.; OLIVEIRA, M. G.. Políticas públicas e desenvolvimento. In: MADEIRA, L. M.. Avaliação de Políticas Públicas. Porto Alegre: UFRGS, 2014.

CASULA, M.. Quem governa na governança (local)? Reflexões teóricas e evidências empíricas. Revista de Administração Pública, Rio de janeiro, v.51, n.6, p.11221138,2017

CLEMENTINO, M. L. M.. Regiões Metropolitanas no Brasil: visões do presente e do futuro. In: COLÓQUIO INTERNACIONAL DE GEOCRÍTICA, 14. Anais. Barcelona: Universitat de Barcelona, 2016.

COCHRAN, C. L.; MALONE, E. F.. Public Policy: perspectives and choices. 5 ed. Washington: Lynne Rienner Publishers, 2014.

COLEBATCH, H.; HOPPE, R.; NOORDEGRAAF, M..

Understanding Policy Work. In: COLEBATCH, H.; HOPPE, R.; NOORDEGRAAF, M.. Working for policy. Amsterdam: Amsterdam University Press, 2010.

FERRÃO, J.. Novas agendas urbanas num contexto de transições globais. Oculum ensaios, Campinas, v.13, n.2, 2016.
FUNTOWICZ, S.; MARCHI, B.. Ciências pós-normal, complexidade reflexiva e sustentabilidade. In: LEFF, E.. A complexidade ambiental. 2 ed. São Paulo: Cortez, 2010.

GODARD, O.. A gestão integrada dos recursos naturais e do meio ambiente; conceitos, instituições e desafios de legitimação. In: VIEIRA, P. F.; WEBER, J.. Gestão de recursos naturais renováveis e desenvolvimento: novos desafios para a pesquisa ambiental. São Paulo: Cortez, 1997.

JAMES, P.. Urban sustainability in theory and practice: circles of sustainability. New York: Toutledge, 2015.

JORGE, P. R.; BRUNA, G. C.. Governança municipal como ferramenta para o desenvolvimento sustentável. In: PHILIPPI JUNIOR, A.; ROMÉRO, M. A.; BRUNA, G. C.. Curso de Gestão Ambiental. 2 ed. Barueri: Manole, 2014

LEITE, C.. Cidades sustentáveis, cidades inteligentes: desenvolvimento sustentável num planeta urbano. Porto Alegre: Bookman, 2012.

LIMA, L. L.; D'ASCENZI, L.. Estrutura normativa e implementação de políticas públicas. In: MADEIRA, L. M.. Avaliação de Políticas Públicas. Porto Alegre: UFRGS, 2014.

LOWI, T. J.. Four Systems of Policy, Politics, and Choice. Public Administration Review, v.32, n.4, p.298-310, 1972.

LUZZI, D.. A 'ambientalização' da educação formal: um diálogo aberto na complexidade do campo educativo. In: LEFF, E.. A complexidade ambiental. 2.ed. São Paulo: Cortez, 2010.

MALHEIROS, T. F.; COUTINHO, S. M. V.; PHILIPPI JUNIOR, A.. Desafio do uso de indicadores na avaliação da sustentabilidade. In: PHILIPPI JUNIOR, A MALHEIROS, T. F.. Indicadores de sustentabilidade e gestão ambiental. Barueri: Manole, 2012.

MARQUES, E.. As políticas públicas na ciência política. In: MARQUES, E.; FARIA, C. A. P.. A política pública como campo multidisciplinar. São Paulo: Unesp; Rio de Janeiro: Fiocruz, 2013.

MIRANDA, L. I. B.. A reforma urbana, as políticas territoriais e a questão urbana-rural: uma integração necessária. In: BITOUN, J.; MIRANDA, L.. Desenvolvimento e Cidades no Brasil: contribuições para o debate sobre as políticas territoriais. Recife: Observatório das Metrópoles, 2009.

MORONI, J. A.. O direito à participação no governo Lula. In: AVRITZER, L.. Experiências nacionais de participação social. São Paulo: Cortez, 2009.

PARADA, E. L.. Política y Políticas Públicas. In: SARAVIA, E.; FERRAREZI, E.. Políticas públicas. Brasília: Enap, 2006. 
PEREIRA, L. C.; RÍMOLO, L. G.; OSZLAK, O.; CATALÁ, J. P.; PRZEWORSKI, A.; CONDE, E. A.; GRAU, N. C.. Uma Nova Gestão Pública para América Latina. Centro Latino Americano de Administração para o Desenvolvimento, 1998.

RIDDELL, R.. Sustainable Urban Planning: tipping the balance. Londres: Blackwell Publishing, 2004.

ROSA, T. S.. Os fundamentos do pensamento ecológico do desenvolvimento. In: VEIGA, J. E.. Economia socioambiental. São Paulo: Senac, 2009.

ROVER, O. J.; MUSSOI, E. M.. A reinvenção da relação estado-sociedade através da gestão pública descentralizada: uma análise da descentralização política em Santa Catarina, Brasil. In: DALLABRIDA, V. R.. Governança territorial e desenvolvimento: descentralização político-administrativa, estruturas subnacionais de gestão do desenvolvimento e capacidades estatais. Rio de Janeiro: Garamond, 2011.

SACHS, I.. Em busca de novas estratégias de desenvolvimento. Revista Estudos Avançados, São Paulo, v.9, n.25, p.29-63, 1995. DOI: https://doi.org/10.1590/S0103-40141995000300004

SALAMON, L. M.. The New Governance and the Tools of
Public Action: an introduction. In: SALAMON, L. M... The tools of government: a guide to the new governance. Oxford: Oxford University Press, 2002.

SALAT, S.. Uma nova abordagem à criação de valor urbano. In: RODRIGUES, F. M.. Por uma estratégia de cidade sustentável: expansão urbana planeada, quadro legal e financiamento autárquico. Porto: Afrontamentos, 2017.

SARAVIA, E.. Introdução à teoria da política pública. In: SARAVIA, E.; FERRAREZI, E.. Políticas públicas. Brasília: Enap, 2006.

SOUZA, C.. Estado da arte da pesquisa em políticas públicas. In: HOCHMAN, G.. Políticas Públicas no Brasil. Rio de Janeiro: Fiocruz, 2007.

THOMAS, J. M.; CALLAN, S. J.. Economia ambiental: fundamentos, políticas e aplicações. São Paulo: Cengage Learning, 2014.

UN-HABITAT. World Cities report 2016. Urbanization and development: emerging. United Nations Human Settlements Programme, 2016.

WILHEIM, J.. Cidades: o substantivo e o adjetivo. São Paulo: Perspectiva, 2008.

A CBPC - Companhia Brasileira de Produção Científica (CNPJ: 11.221.422/0001-03) detém os direitos materiais desta publicação. Os direitos referem-se à publicação do trabalho em qualquer parte do mundo, incluindo os direitos às renovações, expansões e disseminações da contribuição, bem como outros direitos subsidiários. Todos os trabalhos publicados eletronicamente poderão posteriormente ser publicados em coletâneas impressas sob coordenação da Sustenere Publishing, da Companhia Brasileira de Produção Científica e seus parceiros autorizados. Os (as) autores (as) preservam os direitos autorais, mas não têm permissão para a publicação da contribuição em outro meio, impresso ou digital, em português ou em tradução. 